\title{
Spinal Chordoma
}

National Cancer Institute

\section{Source}

National Cancer Institute. Spinal Chordoma. NCI Thesaurus. Code C5156.

A slow-growing malignant bone tumor arising from the remnants of the notochord and occurring in the spine. It is characterized by a lobulated growth pattern, myxoid stroma formation, and the presence of physaliphorous cells. 